\title{
INFLUENCE OF DIGITAL ADVERTISING ON SOCIAL MEDIA BRAND AWARENESS IN NIGERIA
}

\author{
Ada Mac-Ozigbo \\ National Open University of Nigeria, Abuja \\ Daniel Cross Ogohi \\ Nile University of Nigeria, Abuja
}

$\&$

Abdullahi Shehu Araga

National Open University of Nigeria, Abuja

\begin{abstract}
This research examined the Influence of Digital Advertising on Social Media brand awareness in Nigeria. Social media influencers play a vital role which entices brands to pursue them. It is more likely for a consumer to trust a brand that collaborates with an influencer than to trust the brand exclusively. It is found that influencer marketing has impacted the purchasing decision of Nigerians when online. Though many of the purchasers may have positive experience purchasing online, few of them may actually share their experience. Meaning it is more likely for them to share a negative experience in purchasing a product. Extensively, this examination is an interpretive research which applies a serious writing survey. Study originates from secondary data. The strategy for this examination is basic reasonable investigation. From this research, the following recommendations were made; that influencers are highly effective and important at bringing awareness to a brand on social media. And they are also effective in influencing consumers to make the final purchasing decision. Businesses and brands should all partake in influencer marketing as it will help increase sales and the overall brands success.
\end{abstract}

Keywords: digital marketing, influencer marketing, social media and online shopping.

\section{Introduction}

With digital technology small, medium and larger sized companies can gain vital information like the age, gender, and income of users, and how they respond to different aspects of the products and those of competitors. Traditional advertisements were contextual, meaning they were put in specific places or contexts where advertisers expected people to be commercials during TV, billboards and radio, places with a lot of eyes and people. Advertisers had to procure all of the persuasive techniques and logical fallacies into expensive ads and hope the right people will see. But that was before the Internet, smart phones, social media and geo-location.

The quondam advertisers did not know who saw their ads or how well they were doing. Because of this, they targeted groups based on broad demographics: teenagers, families, women, and so on. The issue is that it is not specific enough, so the viewers got incentivized ads. Facebook has 2.38 billion users (Hutchinson, 2019). YouTube has 2 billion users and 400 hours of videos are uploaded to YouTube every minute worldwide (Mohsin, 2019).

Since the birth of mass media, advertisers have been looking for ways to make sure their ads reach the right people. With the Internet, companies of all scale can make online market 
research and acquire all the information they need to stay above competition. Both large and small companies can take traditional market research methods and adapt them to the Web. The result is an affordable means for businesses to learn more about their online customers' needs and wants. For online businesses, development, marketing, and intense competition leave little room for mistakes. A lot of effective and inexpensive online marketing research techniques have been developed. By using these tools, any business of any size can get detailed customer information fast, and for a fraction of the cost of traditional offline methods. The Internet can scrutinize large numbers of consumers promptly, and recuperate levels of information previously unprocurable at any price.

Precise targeting is one of the features of digital advertising, which allows for targeted campaigning where the customers see ads due to their user preferences. Here, customers get only what they ask for because social media platforms have algorithms, which record user preferences. This helps increase the chances of sales and cuts down the cost of marketing.

Many businesses had problems transitioning into fully digits firms. Even in 2017 some businesses didn't still take their social media presence seriously, which can be very detrimental to sales. More than $80 \%$ of consumers expect brands to be on Facebook (Clark-Ginsberg, 2017). This is why young entrepreneurs seized this opportunity and created social media marketing agencies. These are advertising agencies that seek local businesses who they know are performing badly on social media and then the agency uses the social media account of the business to increase follower engagement or to generate potential customers for the business in order to increase sales. The local business then pays the social media-marketing agency for their services. Different social media marketing agencies differ in the services they offer. The services include social media audit, social media publishing, competition analysis, social media marketing strategy and a few more. Many of these agencies offer stand-alone services (Monica, 2020). As technology, keeps evolving these services keep changing, so they are far from constant.

The strategies of advertising on social media keep increasing. Moreover, as this happens, marketers will need to keep up to date with the online apps available. Many of these apps, such as payment gateways are geographically unavailable to Nigeria. If Nigerian marketers made more of an effort in procuring the latest social media strategies, then there will be better access to the best digital resources. Einstein did say that insanity is doing the same thing repeatedly and expecting different results. Marketers failing to adopt the latest strategies could come from laziness, ignorance or blind faith (Traphagen, 2018). Lack of effort comes from lack of knowledge of the benefits of efficient social media marketing strategies such as content marketing and influencer marketing. There are no influencer marketing tools such as 'Musefind' or 'Upfluence' available for use in Nigeria (Techpoint, 2018). This study will shed light on the effect of influencer marketing as a strategy on social media brand awareness. The main objectives of this study are to establish the effect of social network on online buyer behaviour; ascertain the influence of digital marketing on social media buyer response; and determine to what extent influencer marketing affects social media brand awareness.

\section{Literature Review}

\section{Social media and advertising}

Over the past few years social media has changed the world of marketing. Social media is one of the least expensive ways to gain brand awareness for a business. SMM stands for social 
media marketing. Business owners have figured out that SMM is a method that takes very little money to accomplish huge results (Chon, 2010).

\section{Social Network}

A social network is made up of a set of individuals or organizations dyadic ties, and other social interactions between actors. Digital social networks are a focus on online dyads. It is the use of web sites or apps for people to connect with each other and allows them to share content and interact. These networks make it possible to give all individuals a platform to share their experiences and knowledge, which is necessary to build a more inclusive society. To advance our knowledge of (social media) engagement and the consequences for advertising embedded in social media platforms, we adopt the engagement experience framework. This framework suggests that digital engagement develops from digital experiences and has three distinctive characteristics (Calder, Isaac, and Malthouse 2016).

\section{Digital Marketing}

When compared to traditional marketing, digital marketing has an edge when it comes to the consumer response and behavior analysis. Billboard, TV, radio, magazines and any form of print have lack measurable feedback from consumers and are also much more costly. Corporations see digital marketing as communication value to their customers using digital tools. These digital tools include social media, search engine optimization, blogging, and online pay per click, E-mail marketing and video creation. The concept of digital vs traditional advertising focuses more on the tools, rather than the strategy behind them. As consumer media consumption trends tends to shift away from traditional and towards more digital content, there will be a time in future where we no longer refer to it as digital market and instead simply call it marketing.

Video marketing can be seen as a subdivision of digital marketing where content creation through methods such as Blogging or Streaming is included. Vlogging being one of the ways in which influencers emerge. Vlogs can create a personalized experience for the audience, and this helps to build an individual's brand. Advertisers are enthusiastically integrating social media into their advertising programs to drive digital engagement. For example, stating "digital engagement is key to us," sports brand Adidas recently announced it will focus its marketing efforts exclusively on digital and social channels (McCarthy 2017).

\section{Influencer Marketing}

Social media influencers play a vital role which entices brands to pursue them. It is more likely for a consumer to trust a brand that collaborates with an influencer, than to trust the brand exclusively (Lou \& Yuan, 2019). Influencer market takes the idea of celebrity endorsement and creates collaboration between influencers and brands. Influencers themselves have a personal brand or reputation which cultivates their organic following. TikTok, a Chinese owned social media platform now available in over 160 countries and has over 1 billion users worldwide, pays influencers $\$ 500$ on average to join the app and post videos on it. Tiktok, penetrated the US, EU markets by collaborating with influencers across YouTube, Instagram and Snapchat (Doyle, 2020).

\section{Nudge Theory}

Advertisers try to convince customers to buy things, but nudging is about influencing customers without their knowing. Nudge can be used as a verb, like if saying "to nudge someone away". Richard Thaler and Professor Cass Sunstein created the Nudge theory in the 
2008 book called Nudge: Improving Decisions about Health, Wealth, and Happiness. This theory is in behavioral sciences and behavioral economics in which it highlights effects in decision making and behavior of groups and individuals. It is a system of subtle encouragements based on the advanced knowledge of the decision-making process. This theory is also implemented in politics as much as in business. The first government to start using it was the Obama administration in 2009, which was just a year after the Authors finished the book. Next to implement the theory was the United Kingdom, then German, Australia, Singapore and New Zealand.

Nudges theory is very useful business, politics, economics and sociology. For business, these biases, emotions and social interactions that influence people is highly important for digital marketers. According to Richard Thaler (2008), marketers may see it as a responsibility to supply people with as much information as possible but ignore the issue of information overload. A better strategy would be to simplify the information to the right amount and quality that will nudge the viewer to making the right decision. Since advertisers are entirely aware of social influences, they will write things like "most people prefer", on the product in which they are selling, and this strategy that is used on consumers implements a social pressure bias. A Nudge can free people from any specific bias that they have, but it can also lead them into other ones. It can be used for both truth and deception, which is normally the position any advertiser finds themselves in, especially on social media.

Unrealistic optimism is also another bias which makes lotteries very successful. People are often subject to having their senses fail them when on social media, as it dispenses a platform for profuse scams. A lot being 'get rich quick' advertisement where user is asked to put in a little money in order to get back exponential returns, or a guru who is selling an online course which isn't even worth the cost. Then the advert shows statistics on how many other people have already put their money in and gotten returns, or for the gurus case, maybe in form of testimonials of how many other people have benefited from the course. The key words being 'other people', because this creates a social nudge which influences people to make the decision of buying.

\section{Reciprocity Bias}

This Bias is a tendency to reciprocate the action of others, which created a wave of indebtedness. The tendency comes as a social norm, which says that if someone gives something or helps another in any way, then the other person is obliged to return the favor. This could make the giver to ask for something in return, rather than having to wait for a voluntary reciprocation or ask for more than was given. Anthropologists view this tendency as universal. Other animals such as crabs and monkeys also have this tendency. A common example of reciprocity is the tipping of waiters in restaurants (Hollingworth, 2015). Reciprocity also works at the level. People like people who like them and dislike those who don't. Often times this can create a self-fulfilling prophecy. Dr Robert Cialdini included this principle in his book Influence: The Psychology of Persuasion. Customers know that a business, no matter how altruistic it portrays itself to be, is mainly trying to make a profit. And this is ok, as customers do not resent a business for doing what it needs to do to survive. However, customers react negatively when a business's outreach is clearly one-sided (Fiorella, 2014). Marketers that use the reciprocity bias will better leverage the principle for their own evolutionary advantage. One way is by offering a free sample of their product or service. This could be by way of physical samples, free trials product demos, or some other offer to prospective customers. This makes it much tougher for customers to walk away (Narayanan, 2016). 
Knoll (2016) reviewed multiple articles which was done because most studies failed to provide an in-depth analysis of advertising in social media. The study made use of two international academic databases which were the Business Source Premier and Communication and Mass Media Complete. The articles being searched were required to contain terms such as 'Facebook', 'YouTube', 'social media', 'social web' and 'web 2.0'. The search revealed 520 articles but was reduced to 51 articles. The search was limited to peer-reviewed academic journals. The studies found that researchers and advertisers are still missing a general overview of how companies advertise in social media. It also found that targeting is a very relevant area for further research.

Simon (2015) conducted a study to find out the effectiveness of social media marketing in the promotion of brands or products towards consumers. One of problems asked what social media marketing tools are used. The study determined the effectiveness of the use of social media marketing tools of 30 different business companies. The research made use of exploration, explanation and description. The study used quota sampling and divided the respondents into frequent and seldom social network users. The researcher formulated a structured questionnaire consisting of eight questions. The respondents were approached for interview using guide questions. Statistics treatment of the data was computed using SPSS (statistics package for social sciences). The study found that Facebook was the most used social media marketing tool, followed by twitter then Vlogs.

Lou \& Yuan (2019) administered an online survey among social media users who followed at least one influencer. Participants answered four screening questions, with two of those questions asking about their social media use and influencer following habits, paid all of the participants who answered the four screening questions $\$ 0.10$, and the qualified participants who completed the full survey earned an additional \$1.19. SmartPLS 3 to perform both measurement validation and structural modeling. Results also suggest that influencers' informative posts may contribute to their followers' trust in their branded content and subsequently may affect purchase intents. Influencer's trustworthiness, attractiveness, and perceived similarity (to their followers) positively influenced their followers' trust in their branded posts, may be because influencers, by default, have a status of expertise among their followers. Influencers' expertise and attractiveness help boost followers' brand awareness.

Yazdanparast et al (2016) examined the role of social media marketing and consumer-based brand equity in the $21^{\text {st }}$ century. The whole purpose or reason why the study was done in the first place was to know if social media marketing had significance on the consumer-based equity branding done specifically in the $21^{\text {st }}$ century. The information they gathered was through paper and pencil but contained up to 37 questions. First were questions to respondents, asking about their history with social media and which platforms they were familiar with. Then came up questions about which brands the respondents followed on social media. Out of the questionnaire, most of the participants were aged between 18 and 25 with the average age being 20 in 162 feasible responses. This was useful as people who fall under these sorts of ages normally curate online Vlogs on social media. Respondents chose the sort of brands they followed. Beauty, sports, food, electronics, entertainment, department stores and automotive were listed as the accessory brands. $44 \%$ of the participants followed one of those accessory brands. Some only followed one brand these were $25.6 \%$ of them. $54.9 \%$ were the ones who followed 2-5 brands. The ones who followed 6-10 brands were $14.6 \%$ of them. A small percentage followed more than 10 brands and this was $14.6 \%$ of participants. Besides the types of brands, they followed, information was gained on the reason why they followed brands in 
the first place. Exactly $27.2 \%$ followed brands because they were interested in the products offered by those brands. This will be seen as good news for drop shippers, as these marketers will be able to gain large amount of sales from consumers have interest in a brand because of its products. $14.8 \%$ followed brands just for news. 36\% were interested in finding sales coupons. A large $70 \%$ said brands influenced their purchase decision. The results of the study showed that social media marketing produced positive responses in consumer's perceptions of the products presented to them. It gives the products a higher perceived value. This means that social media marketing improves consumer-based branding. The study encourages marketers such as people drop shipping to make a good use of how good branding can change customers' perceptions and views to make them perceive a higher prestige in products that are offered to them. Some of the limitations of the research were that it used college students and people who are generally on the younger side of the population of people on social media. So, it may not present a general view of all social media users.

\section{Methodology}

Philosophically, this examination is an interpretive research which applies a serious writing survey. Study originates from secondary data. The strategy for this examination is basic reasonable investigation. A lot of dialogs about the reason and plan of the examination have been done so as to improve the structure of the draft. The last game plan of research body has been cooperatively made to enable professionals to increase better understanding into the reasonable and progress of the investigation. This study focused on social media users who were engaged shoppers. Analysis was carried out on social media users in Abuja. Considering Marketing Techniques on social media, the study analyzed how users interacted with influencer marketing. Information gathered from consumers was helpful in determining how effective social media advertising is for businesses.

\section{Discussion and Conclusions}

Based on this study, we, however, inferred that social networking, digital marketing and influencer marketing have influenced the purchasing decision of Nigerians when online. Though many of the purchasers may have a positive experience purchasing online, only a few of them may actually share this experience. This however means that it is more likely for them to share a negative experience in purchasing a product, poor customer service or non-delivery. Finally, to answer the question of how digital advertising influences social media brand awareness, the conclusion is that influencers are highly effective and important at bringing awareness to a brand on social media. And they are also effective in influencing consumers to make the final purchasing decision. The followers of an influencer seem to have emotional connection toward the influencer. This can have a massive effect on the follower's feeling for the products being promoted to them by the influencer. It is common that the followers can search for this product on different social media platforms, mainly because the biggest social media platforms are huge sources of information and news.

This study focused mainly on social media users in Abuja though the numbers may be smaller due to the fact that Abuja has one of the highest number of people engaged in online shopping; second only to Lagos. Research like this serve to be very helpful to brand and business owners when they go into market research and helps in planning for their future decisions. The information gotten from this study shows businesses and brands should all partake in social networking, digital advertising and influencer marketing as these will help increase sales and the overall brands success. Influencer marketing ends up being very important in the overall marketing of businesses. 


\section{References}

Clark-Ginsberg, E. (2017, February 1). New Data: Why Your Fans Aren't Following You On Social Media. Hubspot.https://blog.hubspot.com/marketing/data-social-media-fansnot-following-brand

Cohn, M. (2010, September 2). The Impact of Social Media on Advertising. CompuKol Communications.https://www.compukol.com/the-impact-of-social-media-onadvertising/

Doyle, B. (2020, March). Influencer Marketing Case Study: TikTok (Bytedance) | NeoReach. NeoReach | Influencer Marketing Platform. https://neoreach.com/case-studies/tik-tok/

Hollingworth, C. (2015, July 25). Bias In The Spotlight: Reciprocity. Research Live.https://www.research-live.com/amp-page.html?id=4013678\&name=bias-in-thespotlight-reciprocity

Hutchinson, A. (2019, April 24). Facebook Reaches 2.38 Billion Users, Beats Revenue Estimates In Latest Update. Social Media Today.https://www.socialmediatoday.com/news/facebook-reaches-238-billion-usersbeats-revenue-estimates-in-latest-upda/553403/

Lou, C., \& Yuan, S. (2019). Influencer Marketing: How Message Value and Credibility Affect Consumer Trust of Branded Content on Social Media. Journal of Interactive Advertising, 19(1), 58-73. https://doi.org/10.1080/15252019.2018.1533501

Mohsin, M. (2019, December). 10 YouTube Statistics 2020 Every Marketer Should Know [Infographic]. Oberlo. https://www.oberlo.com/blog/youtube-statistics

Monica. (2020, February 11). What Do Social Media Agencies Do? SMhack.https://smhack.io/blog/what-do-social-media-agencies-do/

Myers Leonard, J. (2020, April 9). The Reciprocity Bias, Or Simple Acts Of Kindness? The Behaviours Agency. https://thebehavioursagency.com/the-reciprocity-bias/

Narayanan, S. (2016, March 17). Cognitive Biases: Reciprocity. Zaius. https://www.zaius.com/learn/cognitive-biases-reciprocity/

Oza, H. (n.d.). 10 Advantages of Digital Marketing over Traditional Marketing. Prowly Magazine. Retrieved March 4, 2020, from https://prowly.com/magazine/advantagesof-digital-marketing-over-traditional-marketing/

Techpoint Africa. (2018, February 21). How to Make Influencer Marketing Work For You In Nigeria. Retrieved from: https://techpoint.africa/2018/02/21/make-influencermarketing-work-nigeria/

Traphagen, M. (2018, February 12). 6 Outdated Social Media Tactics That Need To Die. Search Engine Journal. https://www.searchenginejournal.com/outdated-social-mediatactics/227421/amp/ 
Yazdanparast, A., Joseph, M., \& Muniz, F. (2016). Consumer based brand equity in the 21st century: an examination of the role of social media marketing. Young Consumers, 17(3), 243-255. https://doi.org/10.1108/YC-03-2016-00590/ 